\title{
Tinnitus in Adults, a Health Problem: Implications for the Society and the Scientific Community
}

\section{Acufeno em Adultos, um Problema de Saúde: Implicações para a Sociedade e para a Comunidade Científica}

Haúla F. Haider ${ }^{1}$, João C. Paço1, Deborah A. Hall ${ }^{2}$

Corresponding Author/Autor Correspondente: Haúla Faruk Haider [haula.f.haider@jmellosaude.pt]

\section{ABSTRACT}

Tinnitus is a phantom sound perceived in the absence of external acoustic stimulation, which is only heard by the affected person. It is described in a variety of ways and can be a single sound or combination of different sounds. Tinnitus is related to many other conditions and has an impact in the quality of life of the affected person. However, pathophysiological mechanisms underlying tinnitus and their basic biological remains unknown. One of the major challenges, concerning the heterogeneity of the tinnitus condition, is the lack of standardization in research and clinical management. For this, the TINNET, a European Cost Action for research, has the main objective to develop better strategies for diagnosis and management. The establishment of guidelines for clinical diagnosis, treatment, neuroimaging assessments and outcome assessment, through the identification of clinically meaningful tinnitus subtypes, provides an important basis for the standardization of clinical research and management of tinnitus.

KEYWORDS: Adult; Health Promotion; Tinnitus

1. ENT Department, Hospital CUF Infante Santo - NOVA Medical School, Lisbon, Portugal

2. University of Nottingham Malaysia, Jalan Broga, 43500 Semenyih, Selangor Darul Ehsan, Malaysia. National Institute for Health Research (NIHR) Nottingham Biomedical Research Centre, Division of Clinical Neuroscience, School of Medicine, University of Nottingham, Nottingham, UK. ORCID iD: 0000-0002-3804-1452.

Received/Recebido: 20/08/2018 - Accepted/Aceite: 29/09/2018 


\section{RESUMO}

O acufeno consiste numa perceção sonora na ausência de correspondente estimulação acústica externa, que é apenas ouvido pela pessoa afetada. É descrito de várias formas e pode ser um som único ou uma combinação de diferentes sons. O acufeno está relacionado a outras condições e tem impacto na qualidade de vida da pessoa afetada. No entanto, os mecanismos fisiopatológicos subjacentes ao acufeno e as suas características biológicas básicas permanecem desconhecidos. Um dos maiores desafios, devido à heterogeneidade subjacente ao acufeno, é a falta de padronização na pesquisa e no tratamento clínico. Para isso, a TINNET uma rede de investigação europeia, tem como principal objetivo desenvolver melhores estratégias de diagnóstico e tratamento. A criação de diretrizes para o diagnóstico clínico, tratamento, avaliações de neuroimagem e avaliação de resultados, através da identificação de subtipos do acufeno clinicamente relevantes, fornecem uma base importante para futuras meta-análises e otimização da terapêutica do acufeno.

PALAVRAS-CHAVE: Acufeno; Adulto; Promoção da Saúde

\section{SYMPTOMS, CAUSES AND GLOBAL BURDEN}

Tinnitus derives from the latin word tinnire (to ring). Tinnitus is a symptom that comprises the perception of a sound in the ears or head, without a corresponding external acoustic stimulus. The percept can be a simple sound like hissing, sizzling and ringing, or a complex composite of sounds, or multiple separate sounds. ${ }^{1}$ Since ancient times, we can find records reporting the condition and its treatment. For example, an Egyptian medical document originating in 2500 BC called the Ebers Papyrus refers to the 'bewitched ear' and recommends intra-aural infusions as a treatment. ${ }^{2,3}$

Tinnitus can cause significant emotional reactions to it and negatively impact the quality of life of the affected person. Clinicians talk about habituation to tinnitus so that over time symptom severity tends to diminish. ${ }^{4}$ Indeed, a systematic review that pooled outcomes for 'no-intervention' controls across a number of randomized controlled trials also confirmed a small but consistent reduction in symptom severity. ${ }^{5}$ Those individuals who do remain disturbed by their tinnitus over the longer term may be those with some additional comorbidity such as generalized anxiety, depression, hyperacusis, headache, and vertigo, which may make the individual more prone to focus attention on their tinnitus symptoms. ${ }^{6-10}$

There are two broad categories of tinnitus; objective and subjective. Tinnitus can be objective when it is audible by others, but these account for less than $1 \%$ of all cases. Objective tinnitus mainly originates from vascular or muscular problems in the vicinity of the ear or in the head and neck. ${ }^{11,12}$ Tinnitus can be pulsatile and if it is synchronous with the heart beat then a vascular pathology might be suspected. In particular, when there is a unilateral pulsatile tinnitus that is synchronous with the heart beat then there is an 80\% higher probability that the origin is a vascular loop adjacent to the VIIIth cranial nerve. ${ }^{13}$

In the majority of cases, tinnitus is subjective because it is audible only by the person affected. Subjective tinnitus can be associated with a variety of medical conditions, both otological and non-otological. ${ }^{14-16}$ For example, a low frequency tinnitus is most typical of Ménière's disease. ${ }^{17}$ However, nearly $30 \%$ of all tinnitus cases are considered to be idiopathic. ${ }^{14-16}$ Tinnitus etiology can be multifactorial and complex, and given its often gradual onset, even careful medical history taking cannot always identify a cause.

Epidemiological case control studies confirm hearing loss and ageing, ${ }^{18}$ noise exposure ${ }^{19-21}$ exposure to ototoxic medication ${ }^{22,23}$ and depression ${ }^{24}$ as some of the most common risk factors. Nearly $40 \%$ of people with tinnitus are also reported to experience some degree of sound tolerance (hyperacusis), ${ }^{25}$ but whether there is a pathophysiological link between these two conditions remains unknown. Other known associations include sleeping problems, ${ }^{26-28}$ head or neck injury ${ }^{29}$ and emotional exhaustion. ${ }^{30}$ For some authors tinnitus is regarded as the result of chronic stress and related immune response. $^{31}$

With respect to hearing loss, associations are more than simply having both conditions. When a hearing loss is present, the tinnitus frequency usually matches the region of greatest threshold losses, especially in the case of down-sloping sensorineural hearing loss profiles. ${ }^{32}$ Nevertheless, not everyone with a hearing loss has tinnitus, and some people with tinnitus have a normal clinical audiometric profile. 
It is widely posited that if prognostic indicators and clinically meaningful subtypes or profiles of tinnitus could be identified then this would be an effective approach to reducing the variable responsiveness to the different management options currently available. However, pathophysiological mechanisms underlying tinnitus are so far elusive and so, without this basic biological understanding and the identification of tinnitus biomarkers, these goals have not yet been achieved.

It is estimated that one in ten people have tinnitus, and so the global burden of tinnitus is very high. ${ }^{33}$ Information about the prevalence of tinnitus is rather patchy. A recent systematic review of adults (aged 18 years or more) found that global prevalence ranged from $1.5 \%$ to $42.7 \% .{ }^{34}$ But many of these studies defined tinnitus in slightly different ways and so this may explain the wide range. For those population-based studies which used the same tinnitus definition, prevalence rate was somewhat narrower (11.9\% to 30.3\%). Examining the study information indicated that prevalence increased with age, and was also slightly higher for men than for women, but this may be explained by occupational rather than biological differences between the sexes.

A large American cross-sectional study found that 21.4 million people have tinnitus, and of those 36\% experience constant tinnitus, 15\% experienced tinnitus at least once every day and $49 \%$ at least once a week. ${ }^{33}$ Concerning tinnitus symptom severity, 7.2\% described their condition as a 'big or very big problem', 20.2\% as a 'moderate problem', and $72.6 \%$ as 'not a bothersome problem.'33 The Tinnitus Functional Index ${ }^{35}$ is an instrument that can be used as a diagnostic tool to grade overall symptom severity and this has five category levels from 'very big problem' to 'not a problem'.

Results from the most recent World Health Organization (WHO) Global Burden of Diseases (2015) reports hearing loss as the fourth leading cause of years lived with disability. Given the strong links between hearing loss and tinnitus, then tinnitus surely follows this trend. It has been recognized that the economic burden to society is high compared to some other chronic conditions. For example, a large prospective Swedish cohort study found that sickness absence at work due to tinnitus and hearing loss increased the risk of future claims for disability pension by three times compared to non-audiological diagnoses. ${ }^{36}$ Furthermore, tinnitus is the most common complaint in modern warfare. For example, the annual disability compensation paid by US department of Veteran's Affairs for tinnitus and hearing loss exceeds $\$ 2$ billion USD. ${ }^{37}$

\section{NEED FOR STANDARDIZATION}

Many people with tinnitus do not seek medical support. Even for those reporting tinnitus as a bothersome problem, the American survey described earlier found that only $50 \%$ had visited a physician for a consultation appointment. ${ }^{33}$ Although there are multiple management options for tinnitus, the majority lack high quality scientific evidence to support strong claims for their benefit. Perhaps of all therapeutic options, cognitive behavioral therapy (CBT) delivered by a qualified clinical psychologist has the most support for its effectiveness in reducing tinnitus symptom severity. ${ }^{38-40}$

Given the heterogeneity of the tinnitus condition, one of the major challenges to advancing the field of tinnitus concerns the lack of standardization in approaches to research and clinical management. To address this, a European consortium gathered together in 2014 under the auspices of a four-year European Cost Action BM1306 "Tinnitus Research Network" (TINNET) (http://tinnet. tinnitusreserch.net/). The main objective of this Action was the creation of an international network for identifying clinically meaningful subtypes of tinnitus and their neurobiological underpinnings in order to develop better strategies for diagnosis and management. TINNET comprised five working groups (WG) covering clinical, database, neuroimaging, genetics and measurement outcomes. These coordinated efforts from basic scientists, technicians and clinicians working in different medical disciplines working together in close collaboration. A set of ambitious interdisciplinary objectives were to create standards for identifying: i) meaningful clinical and demographic characteristics for tinnitus subtyping (WG1), ii) assessing tinnitus-related changes in brain activity associated with different subtypes of tinnitus (WG3), iii) intermediate genetic phenotypes and genetic factors in the pathogenesis of tinnitus (WG4), iv) standards for assessing outcomes after clinical intervention (WG5). Cross-cutting all of these themes WG2 was aimed at establishing an electronic data repository to promote scientific transparency and support data sharing.

The legacy from TINNET is wide ranging. WG1 have gather the opinions of clinical experts using consultation methods to generate an evidence-based good practice guideline for the assessment and management of people with bothersome tinnitus. This is now in the final stage of dissemination but was launched at the $11^{\text {th }}$ Tinnitus Research initiative and $2^{\text {nd }}$ TINNET conference in Regensburg in March 2018. WG3 has established a consensus for neuroimaging data acquisition based on input from tinnitus experts in neuroimaging from across the world. Recommendations for electroencephalography (EEG) 
and magnetoencephalography (MEG) are already available on the TINNET website. The recommendations for magnetic resonance imaging (MRI) are in the final stages of dissemination. WG4 have published an updating study exposing that the available evidence for genetics in tinnitus is scarce and addressing the ideal design of studies concerning tinnitus genetic should use concordance twin studies and optimize patient selection according to phenotype and/or etiology to avoid genetic interpretation bias. ${ }^{41}$ WG 5 have gathered the opinions of many different stakeholders including people with tinnitus as well as professionals using consensus methods to produce recommendations for what tinnitus-related complaints are critical and important to measure when assessing treatment-related benefit. Of interest, these guidelines separately consider sound-based, psychology-based and pharmacology-based interventions, since each of these approaches has a different therapeutic rationale and therefore aims to address different tinnitus symptoms. For WG5, a series of publications has already appeared in various peer-reviewed journals s2-45 $^{4 n d}$ the main findings are again in the final stage of dissemination. The next step is to identify how the different tinnitus-related complaints should be measured. This work will continue over the next few years beyond the initial TINNET funding.

\section{CONCLUDING REMARKS}

TINNET has been an important pan-European project in bringing together a range of multi-disciplinary experts with an interest in tinnitus. The four years have succeeded in generating a tinnitus community. While the guidelines thus created for clinical diagnosis, management, neuroimaging assessments and outcome measurements provide an important basis for standardization, the future challenge will be in ensuring that these recommendations are adopted and implemented on an international scale. Only by working together as a community can we ultimately pave the way to help our patients more effectively manage their symptoms and ultimately to find a cure for this debilitating condition.

CONFLICTS OF INTEREST: The authors declare that they have no conflicts of interest.

FUNDING SOURCES: HFH has received a PhD Grant from José de Mello Saúde.

CONFLITOS DE INTERESSE: Os autores declaram não ter qualquer conflito de interesse na realização do presente trabalho.

FONTES DE FINANCIAMENTO: HFH recebeu uma bolsa de doutoramento da José de Mello Saúde.

\section{REFERENCES}

1. Baguley D, McFerran, D, Hall D. Tinnitus. Lancet. 2013;382:1600-7. doi: 10.1016/S0140-6736(13)60142-7.

2. Heller AJ. Classification and epidemiology of tinnitus. Tinnitus: Advances in evaluation and management. Otolaryngol Clin North Am. 2003 ;36: 239-48.

3. Sandlin RE, Olsson RJ. Tinnitus: It Has a Certain Ring to It. 2000. [accessed Jan 2018] Available from: https://www.audiologyonline.com/articles/tinnitus-it-has-certain-ring-1287

4. Cima RF, Crombez G, Vlaeyen JW. Catastrophizing and fear of tinnitus predict quality of life in patients with chronic tinnitus. Ear Hear. 2011; 32:634-41. doi: 10.1097/AUD.0b013e31821106dd.

5. Phillips JS, McFerran DJ, Hall DA, Hoare DJ. The natural history of subjective tinnitus in adults: A systematic review and meta-analysis of no-intervention periods in controlled trials. Laryngoscope. 2018; 128:217-27. doi: 10.1002/ lary.26607.

6. Cima RFF, Vlaeyen JW, Maes I, Joore MA, Anteunis LJ. Tinnitus interferes with daily life activities: a psychometric examination of the Tinnitus Disability Index. Ear Hear. 2011;32: 623-33.

7. Dobie RA. Depression and tinnitus. Otolaryngol Clin North Am. 2003;36: 383-8.

8. Holgers KM, Zöger S, Svedlund L. Predictive factors for development of severe tinnitus suffering-further characterization. Int J Audiol. 2005; 44, 584-592.

9. Kennedy V, Wilson C, Stephens D. Quality of life and tinnitus. Audiol Med. 2004; 2, 29-40.

10. Møller AR. Pathophysiology of tinnitus. Tinnitus: Advances in evaluation and management. Otolaryngol Clin North Am. 2003; 36 :249-66

11. Folmer RL, Martin WH, Shi Y. Tinnitus: Questions to reveal the cause, answers to provide relief. J Fam Pract. 2004; 53: 53241.

12. Sismanis A. Pulsatile tinnitus. Otolaryngol Clin North Am. 2003; 36: 389-402, viii.

13. Chadha NK, Weiner GM. Vascular loops causing otological symptoms: a systematic review and meta-analysis. Clin Otolaryngol. 2008; 33: 5-11. doi: 10.1111/j. 1749-4486.2007.01597.x

14. Martines F, Bentivegna D, Di Piazza F, Martines E, Sciacca $V$, Martinciglio $G$. Investigation of tinnitus patients in Italy: clinical and audiological characteristics. Int J Audiol. 2010:2010:265861. doi: 10.1155/2010/265861.

15. Martines F, Bentivegna D, Martines E, Sciacca V, Martinciglio G. Assessing audiological, pathophysiological and psychological variables in tinnitus patients with or without hearing loss. Eur Arch Otorhinolaryngol. 2010;267:1685-93. doi: 10.1007/s00405-010-1302-3.

16. Martines F, Bentivegna D, Martines E, Sciacca V. Martinciglio G. Characteristics of tinnitus with or without hearing loss: clinical observations in Sicilian tinnitus patients. Auris Nasus Larynx. 2010; 37: 685-93.

17. Havia M, Kentala E, Pyykkö I. Hearing loss and tinnitus in Meniere's disease. Auris Nasus Larynx. 2002; 29: 115-19.

18. Hoffman HJ, Reed GW. Epidemiology of tinnitus. Tinnitus: Theory and management. Ann Otolaryngol Chir Cervicofac. 2004; 16: 41.

19. Nondahl DM, Cruickshanks KJ, Wiley TL, Klein R, Klein BE, Tweed TS. Prevalence and 5-year incidence of tinnitus among older adults: the epidemiology of hearing loss study. J Am Acad Audiol. 2002; 13: 323-31. 
20. Sindhusake D, Golding M, Newall P, Rubin G, Jakobsen K, Mitchell P. Risk factors for tinnitus in a population of older adults: the blue mountains hearing study. Ear Hear. 2003; 24: 501-7.

21. Shargorodsky J, Curhan GC, Farwell WR. Prevalence and characteristics of tinnitus among US adults. Am J Med. 2010; 123 711-18. doi: 10.1016/j.amjmed.2010.02.015.

22. Cianfrone G, Pentangelo D, Cianfrone F, Mazzei F, Turchetta R, Orlando MP, et al. Pharmacological drugs inducing ototoxicity, vestibular symptoms and tinnitus: a reasoned and updated guide. Eur Rev Med Pharmacol Sci. 2011; 15: 601-36.

23. Seligmann H, Podoshin L, Ben-David J, Fradis M, Goldsher M. Drug-induced tinnitus and other hearing disorders. Drug Saf. 1996; 14: 198-212.

24. Zeman F, Koller M, Langguth B, Landgrebe M. Which tinnitus-related aspects are relevant for quality of life and depression: results from a large international multicentre sample. Health Qual Life Outcomes. 2014; 12: 7. doi: 10.1186/1477-752512-7.

25. Anari M, Axelsson A, Eliasson A, Magnusson L. Hypersensitivity to sound: questionnaire data, audiometry and classification. Scand Audiol. 1999; 28: 219-30.

26. Alster J, Shemesh Z, Ornan M, Attias J. Sleep disturbance associated with chronic tinnitus. Biol Psychiatry. 1993; 34: 84-90.

27. Crönlein T, Langguth B, Geisler P, Hajak G. Tinnitus and insomnia. Prog Brain Res. 2007; 166: 227-33.

28. Fioretti AB, Fusetti M, Eibenstein A. Association between sleep disorders, hyperacusis and tinnitus: evaluation with tinnitus questionnaires. Noise Health. 2013; 15: 91-5. doi: 10.4103/1463-1741.110287.

29. Kreuzer PM, Landgrebe M, Schecklmann M, Staudinger S, Langguth B. Trauma-associated tinnitus: audiological, demographic and clinical characteristics. PLoS One. 2012; 7 : e45599. doi: 10.1371/journal.pone.0045599.

30. Hébert S, Canlon B, Hasson D. Emotional exhaustion as a predictor of tinnitus. Psychother Psychosom. 2012; 81: 324-6.

31. Szczepek A, Mazurek B. Tinnitus and Stress. Berlin: Springer International Publishing; 2017.

32. Schecklmann $M$, Vielsmeier $V$, Steffens $T$, Landgrebe $M$, Langguth B, Kleinjung, T. Relationship between audiometric slope and tinnitus pitch in tinnitus patients: insights into the mechanisms of tinnitus generation. PloS One. 2012; 7 : e34878. doi: 10.1371/journal.pone.0034878.

33. Bhatt JM, Lin HW, Bhattacharyya N. Prevalence, severity, exposures, and treatment patterns of tinnitus in the United States. JAMA Otolaryngol Head Neck Surg. 2016; 142: 959-65. doi: 10.1001/jamaoto.2016.1700.

34. McCormack A, Edmondson-Jones M, Somerset S, Hall D. A systematic review of the reporting of tinnitus prevalence and severity. Hear Res. 2016; 337: 70-9. doi: 10.1016/j.heares.2016.05.009.

35. Meikle MB, Henry JA, Griest SE, Stewart BJ, Abrams HB, McArdle R, et al. The tinnitus functional index: development of a new clinical measure for chronic, intrusive tinnitus. Ear Hear. 2012; 33: 153-76. doi: 10.1097/AUD.0b013e31822f67c0.

36. Friberg E, Jansson C, Mittendorfer-Rutz E, Rosenhall U, Alexanderson K. Sickness absence due to otoaudiological diagnoses and risk of disability pension: a nationwide Swedish prospective cohort study. PLoS One. 2012; 7: e29966. doi: 10.1371/journal.pone.0029966.

37. Yankaskas K. Operational readiness: the role of tinnitus research. In 5th International TRI Conference in Tinnitus-The Neuroscience of Tinnitus 2011. [accessed Jan 2018] Available from: https://www.tinnitusresearch.net/images/files/mi-
grated/meetings/files2011/5th\%20TRI\%20Conference\%20 ABSTRACTS.pdf

38. Martinez Devesa P, Waddell A, Perera R, Theodoulou M. Cognitive behavioural therapy for tinnitus. Cochrane Database Syst Rev. 2007; 1: CD005233.

39. Hesser H, Weise C, Westin VZ, Andersson G. A systematic review and meta-analysis of randomized controlled trials of cognitive-behavioral therapy for tinnitus distress. Clin Psychol Rev. 2011; 3: 545-53. doi: 10.1016/j.cpr.2010.12.006.

40. Cima RF, Maes IH, Joore MA, Scheyen DJ, El Refaie A, Baguley DM, et al. Specialised treatment based on cognitive behaviour therapy versus usual care for tinnitus: a randomised controlled trial. Lancet. 2012; 379: 1951-9. doi: 10.1016/S01406736(12)60469-3.

41. Lopez-Escamez JA, Bibas T, Cima RF, Van de Heyning P, Knipper M, Mazurek B, et al. Genetics of tinnitus: an emerging area for molecular diagnosis and drug development. Front Neurosci. 2016; 10: 377. doi: 10.3389/fnins.2016.00377.

42. Hall DA, Haider H, Szczepek AJ, Lau P, Rabau S, Jones-Diette J, et al. Systematic review of outcome domains and instruments used in clinical trials of tinnitus treatments in adults. Trials. 2016; 17: 270. doi: 10.1186/s13063-016-1399-9.

43. Hall DA, Fackrell K, Li AB, Thavayogan R, Smith S, Kennedy V, et al. A narrative synthesis of research evidence for tinnitus-related complaints as reported by patients and their significant others. Health Qual Life Outcomes. 2018; 16: 61. doi: 10.1186/s12955-018-0888-9.

44. Hall DA, Smith H, Heffernan E, Fackrell K. Recruiting and retaining participants in e-Delphi surveys for core outcome set development: Evaluating the COMiT'ID study. PloS One. 2018; 13: e0201378. doi: 10.1371/journal.pone.0201378.

45. Smith H, Horobin A, Fackrell K, Colley V, Thacker B, Hall DA. Defining and evaluating novel procedures for involving patients in Core Outcome Set research: creating a meaningful long list of candidate outcome domains. Res Involv Engagem. 2018;4:8. doi: 10.1186/s40900-018-0091-5. 